\title{
The Research on the Mobile Drilling Rig for Deep Seabed Shallow Strata
}

\author{
Ziqiang Ren ${ }^{a}$, Feng Zhou ${ }^{b}, *$, Hai Zhu ${ }^{a}$, Peihao Zhang ${ }^{a}$, Jiawang Chen ${ }^{a}$, Peng Zhou ${ }^{a}$, Lieyu Tian ${ }^{b}$, \\ Chunhu Liud, Xiaochao Zhang ${ }^{d}$ \\ ${ }^{a}$ Ocean college, Zhejiang University, Zhoushan, 316021, China \\ ${ }^{b}$ State Key Laboratory of Fluid Power Transmission and Control, Zhejiang University, Hangzhou, 310027, China; \\ ${ }^{c}$ Guangzhou Marine Geological Survey, Guangzhou, 510075, China \\ ${ }^{d}$ School of Oceanography, Shanghai Jiaotong University, Shanghai, 200030, China \\ *Correspondence: madzf@zju.edu.cn
}

\begin{abstract}
At present, the drilling rig for deep seabed shallow strata is widely used in the exploration of ocean cobalt-rich crust resources and other fields, which not only can obtain solid core samples at a specific station, but the operation process is relatively safe. This paper mainly presents the structure and mechanism of mobile drilling rig in acquiring the seafloor cores (up to $1.5 \mathrm{~m}$ long). Based on the function of the AMESim software, the hydraulic propulsion system model of mobile drilling rig is established, which is the basis and core part of the mobile drilling rig. Moreover, the control methods of closed-loop and PID are respectively used to control the hydraulic propulsion system for simulation analysis. Through the comparison of simulation results, it is found that the PID control method is more convincing in verifying the design rationality of hydraulic propulsion system. In the simulation of the PID-controlled hydraulic propulsion system, the co-simulation technology of AMESim and Matlab/Simulink not only establishes the hydraulic model and control model, but also determines the relevant simulation parameters, which is helpful to improve the system simulation efficiency. In its verification deployment in the South China Sea, the mobile drilling rig has been operated for many times at different depths, and some cores have been successfully obtained. Furthermore, the mobile drilling rig has been used during the 55th Voyage of China Oceanic Scientific Expedition supported by China Ocean Mineral Resources R\&D Association. Several sites were explored and a large number of cobalt-rich crust cores were obtained. The powerful theory and sea trails are provided to support for the further research on survey of the abyssal resource.
\end{abstract}

Key words: cobalt-rich crusts, mobile drilling rig, hydraulic propulsion system, dynamic simulation

\section{Introduction}

The ocean, which accounts for $71 \%$ of the earth's surface, is rich in mineral resources. Cobalt-rich crusts and nodules have been regarded as potential future resources for a wide variety of elements such as $\mathrm{Co}$, $\mathrm{Ti}, \mathrm{Mn}, \mathrm{Ni}, \mathrm{Pt}, \mathrm{Zr}, \mathrm{Nb}, \mathrm{Te}, \mathrm{Bi}, \mathrm{Mo}, \mathrm{W}, \mathrm{Th}$, and rare earth elements (REEs) for crusts and $\mathrm{Ni}, \mathrm{Cu}, \mathrm{Co}, \mathrm{Mn}$, Mo, and Li for nodules[1-2]. Cobalt-rich crusts were first discovered in the late 1950s, mainly distributed in the high terrain areas of the Western Pacific and South Pacific [3]. The drilling rig for deep seabed shallow strata is a complex system that integrates mechanical, electrical, hydraulic, optical and other disciplines. Not only can it obtain solid core samples at a specific station, but the operation process is relatively safe, which is widely used in the exploration of ocean cobalt-rich crust resources and other fields [4]. Paul Johnson contracted with Williamson and Associates in 1989 and 1990 to build a world's first subsea 3-m robotic drill, which was onboard the old R/V Thomas G. Thompson [5-6]. The drill built in the U.K. can core up to 5-m deep and was administered by the British Geological Survey, but it is limited by lack of imaging capabilities and it cannot go deeper than $2000 \mathrm{~m}$ due to its cable. This means that many sites of interest to marine investigators cannot be drilled. It is also a problem that the drill cannot image the seafloor so operators cannot be sure whether it has landed on a suitable outcrop [7]. Another example is the GBU-1.5/6000-2 drill built by Russian Northern Geological exploration 
engineering Consortium, which can core up to $1.5 \mathrm{~m}$ deep and was hanged in the form of steel cable [8]. In 2003, Changsha Institute of Mining Research developed the first deep-sea shallow drilling prototype in China, which was designed for $4000 \mathrm{~m}$ depths and can obtain $0.7 \mathrm{~m}$ of 56-mm diameter core [9]. Under the sponsorship of the China National High-tech R\&D Program, the $20 \mathrm{~m}$ seafloor core sampling drill was developed by Hunan University of Science and Technology at the end of 2010, which can drill up to 20-m penetration depth by the way of wire-line coring [10]. Cobalt-rich crusts are mostly distributed on the slopes of seamounts, and the slope is relatively large. These devices, however, cannot choose exploration sites independently, thus severely restricting the comprehensive study of cobalt-rich crusts and nodules. In order to improve survey efficiency, a new method of mobile drilling rig to acquire the core samples of deep sea is proposed.

This paper is organized as follows. First, the structure and working principle of the mobile drilling rig are briefly described. Thereafter, the propulsion system is presented, which is at the heart of the mobile drilling rig. Based on the function of the AMESim software, the hydraulic propulsion system model of mobile drilling rig is established. Moreover, the control methods of closed-loop and PID are respectively used to control the hydraulic propulsion system for simulation analysis. Finally, the simulation results based on data analysis are elaborated. The mobile drilling rig was used successfully and a large number of cobalt-rich crust cores were obtained during the 55th Voyage of China Oceanic Scientific Expedition supported by China Ocean Mineral Resources R\&D Association. In addition, certain suggestions are proposed for future studies.

\section{Structure and composition of the mobile drilling rig}

\subsection{The whole frame}

The mobile drilling rig for deep seabed shallow strata is necessary equipment for marine geologic and environmental investigation, which is designed for $4500 \mathrm{~m}$ depths and can obtain $1.5 \mathrm{~m}$ of $56-\mathrm{mm}$ diameter cores. It mainly consists of drilling unit, hydraulic system unit, propulsion unit and so on. As shown in Figure.1, the mobile drilling rig mainly includes overall framework, the lifting device, buoyancy device, power rotator, drill pipe, solenoid valve box, underwater motor, compensator, and propeller.

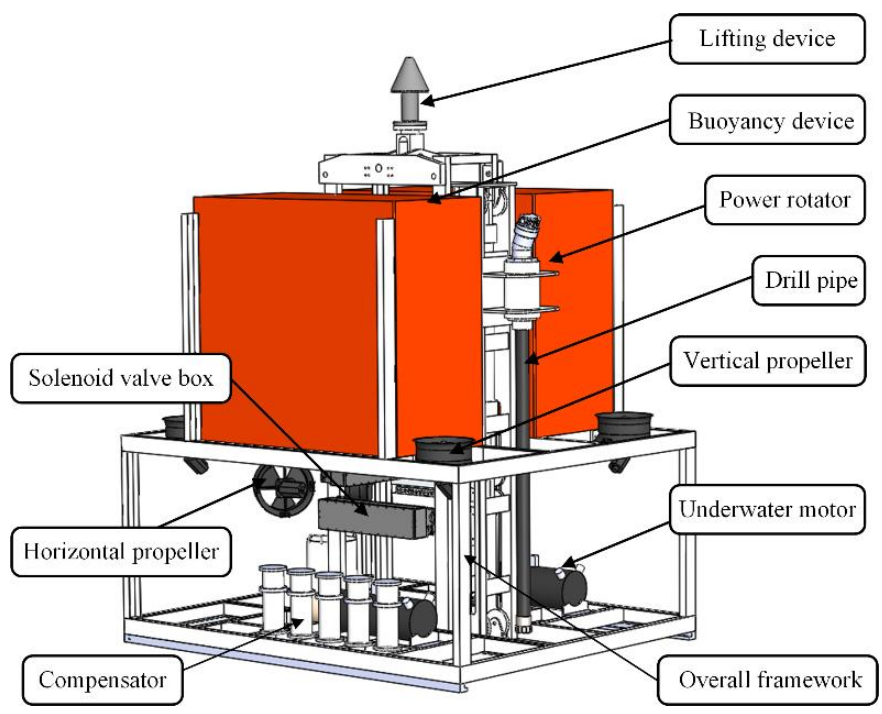

Figure 1. The structure of mobile drilling rig

(1) Drilling unit

The drilling unit, which is used to acquire the cores, is composed of a drilling frame, a drilling driving device, a double length mechanism of wire rope driven by hydraulic cylinder, and a washing mechanism. 
The drilling frame is installed in the center of the drilling rig, the lower part is fixed with the chassis by bolts, and the upper part is connected with the hanger for load bearing. The power rotator is installed in front of the drill frame, and the propulsion driving cylinder and pulley block are located inside the drill frame. The power rotator consists of the sliding frame, a hydraulic motor, bearing box, water inlet, etc. Under the control of the hydraulic system, the hydraulic motor has the functions of high speed and slow speed, which can cooperate with different drilling pressures to achieve the best drilling effect. The stroke of drilling driving device can reach $1.5 \mathrm{~m}$ through the double length mechanism of wire rope driven by hydraulic cylinder with a maximum stroke of $0.9 \mathrm{~m}$. Through the water pump driven by hydraulic motor, sea water is discharged from the water inlet of the drilling driving device, and then flows through bottom of the drilling hole to realize the functions of drilling slag and cooling the drill bit.

(2) Hydraulic system

The hydraulic system mainly consists of the component of underwater motor and hydraulic pump, two general function valve packs (8 station and 16 station), compensators, oil tank with pressure compensation, hydraulic pipeline and various hydraulic actuators. The general function valve packs, including 8 station and 16 station, are extremely compact and lightweight, making them suitable for Work-Class and Inspection ROVs as well as for specialized tooling applications. The 8 station general function valve pack is mainly used to control the propulsion unit, and the 16 station general function valve pack is mainly used to control other various hydraulic actuators.

Each reversing valve and proportional control valve are electromagnetically driven and controlled by an underwater computer control system. When used underwater, the valve pack cover, electronic control interface box and other actuators must be oil filled and compensated using suitable positive pressure compensators.

(3) Propulsion unit

The propulsion unit is mainly composed of four vertical propellers and two parallel propellers and the hydraulic system which drives them to work. In the process of deployment, the compass mounted on the system is used to monitor its attitude in real time. If its attitude changes significantly, the propellers are used to correct the deviation to ensure its stability and reduce the impact of ocean currents. When it is near the sea floor, the mobile drilling rig can move smoothly, and the drilling sites can be selected intuitively and quickly, utilizing the underwater propulsion system and visualization system.

\subsection{Control system}

According to the actual working process, the overall structure of the control system is presented, as shown in Figure.2. The monitoring and controlling unit on the deck can display the operating status of the system in real time, meanwhile, it can operate the mobile drilling rig. The power distribution cabinet provides the high-voltage power supply of the whole system and monitors its insulation status in real time. The sensor signal acquisition unit monitors the working conditions of the system and transmits signals to master computer software in real time. The conversion of analog signals and digital signals is performed by the photoelectric signal conversion and transmission unit. 


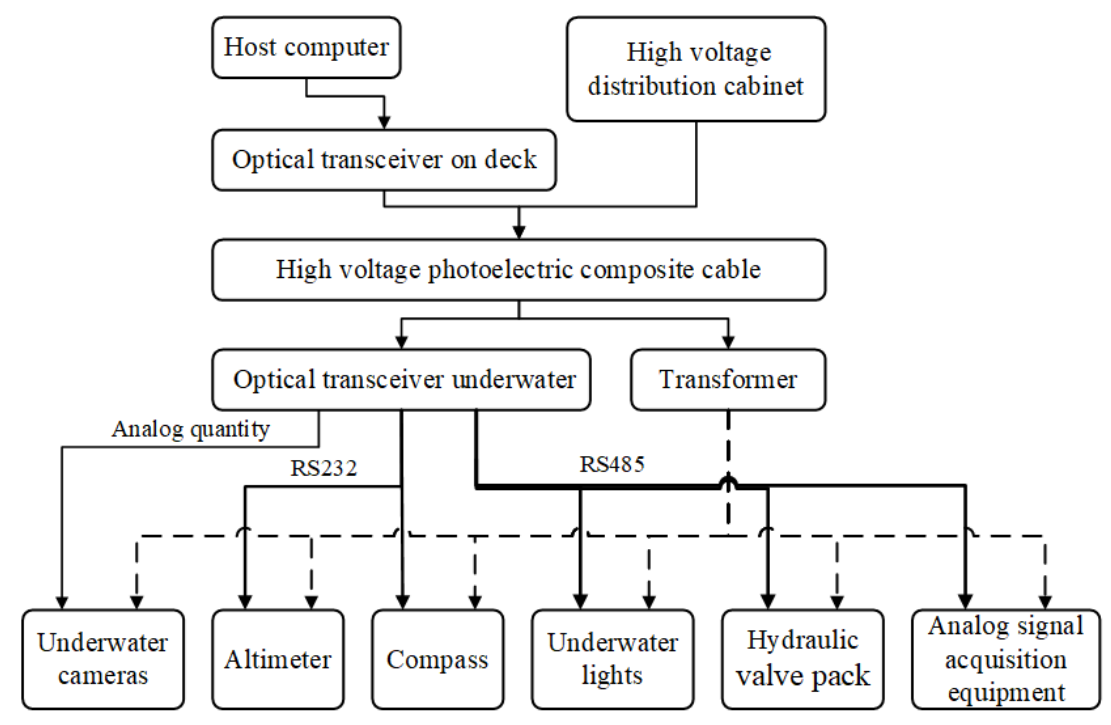

Figure 2. The overall structure of the control system

(1) The hardware design of sensor signal acquisition unit

The mobile drilling rig needs to be equipped with various types of sensors to collect signals from the temperature of the equipment control module, the system pressure of the oil source and some main actuators, the depth of the working ocean and the drilling speed. Moreover, the signals are transmitted to the master computer in real time through the communication unit, which is used for the monitoring system to grasp the operating status of whole system in real time, as well as guiding the technical staff to implement operations. As shown in Figure 3, the control chip of STM32F103C8T6 is used for the microcontroller unit (MCU), which adopts the form of RS485 bus network for communication. The analog output sensor has two forms of voltage output and current output. In order to reduce the space occupied by the circuit board in the underwater interface box, two STM32F103C8T6 chips, which are used to collect voltage and current signals respectively, are integrated on a circuit board, and TTL level signals are used to realize the information transfer between the main and auxiliary control chips. The voltage and current signals are transmitted to the acquisition and conversion circuit after passing through the operational amplifier conditioning circuit for improving the accuracy of analog acquisition. This circuit adopts 16-bit AD7689 analog-to-digital conversion chip and communicates information with the main and auxiliary controllers through SPI communication mode. The four-way leakage detection circuit composed of operational amplifier is used to detect whether the interface box is leaking and transmit status information in real time.

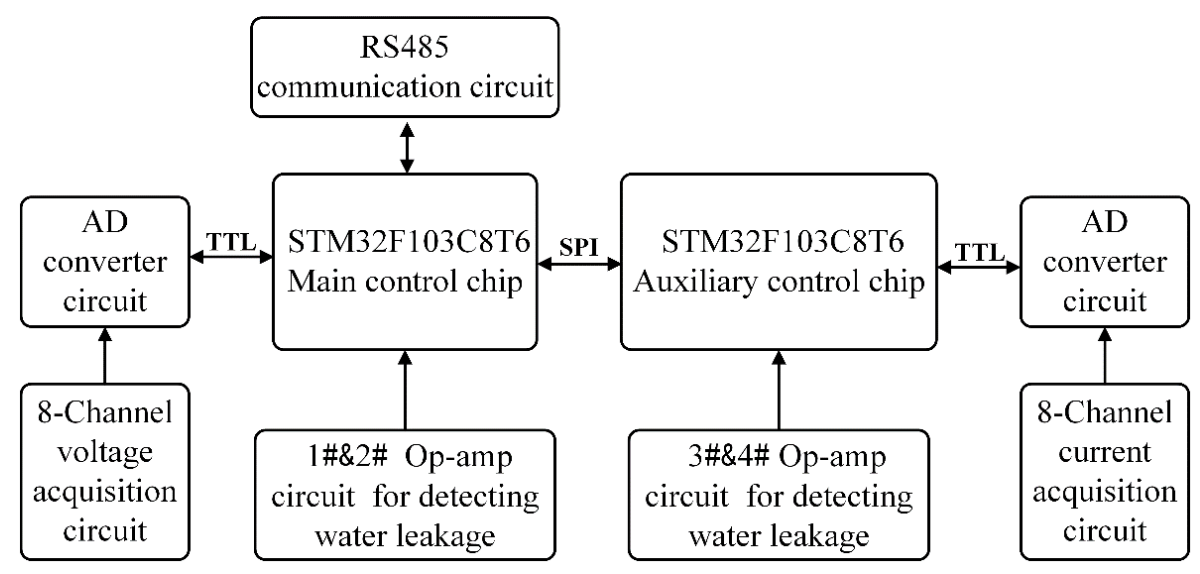


Figure 3. The structure of sensor signal acquisition circuit

(2) Design of peripheral power control unit

The mobile drilling rig is equipped with various types of external equipment with $12 \mathrm{~V}$ and $24 \mathrm{~V}$ power supply. Each equipment requires independent power supply to ensure that it can be isolated separately without affecting the normal use of other equipment when an external device fails. As shown in Figure 4, the MCU based on STM32F103C8T6 is adopted to network with the communication bus through the RS485. The 4-channels $12 \mathrm{~V}$ and 8-channel $24 \mathrm{~V}$ power supply circuits with overload protection function, can supply power to equipment with a rated power of below $30 \mathrm{~W}$ and $100 \mathrm{~W}$. Two leakage detection circuits provide real-time leakage detection for the light compartment.

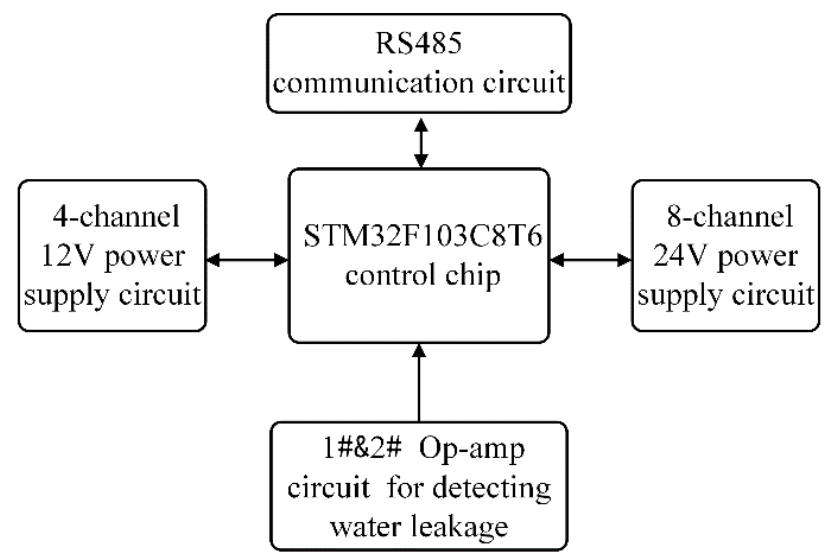

Figure 4. The structure peripheral power control unit

2.3 The design of system software

(1) Design of sensor signal acquisition unit software

The software of sensor signal acquisition unit mainly includes the following functions. Firstly, the initialization of the main control and auxiliary control chips is controlled by this software. Thereafter, the auxiliary control chip collects analog data and sends it to the main control chip at a certain time interval through the serial port. Moreover, the auxiliary control chip can judge the flag of watchdog, and if the flag of watchdog is obtained within the reload time, the watchdog will be updated, otherwise the auxiliary control chip system will be reset. Finally, the serial port of the main control chip interrupts the received data and checks the data frame. The data sent by the auxiliary control chip is stored in the buffer. When the inquiry instruction is sent by the upper computer, the collected data transmitted by the auxiliary control chip or the inquiry command sent by the upper computer are stored if the instruction is correct, and then, the latest data status is written into the data frame and sent to the host computer through the serial port.

(2) Design of peripheral power control unit software

The functions of this software are presented as follows. Firstly, the system is predefined and initialized based on the software. Thereafter, it can receive the data and judge the correctness of the data. If the correct data is received, it will judge whether the data frame ID is the ID of the peripheral power control board, and then the instruction byte of the data frame will be judged, after that, the corresponding IO port is operated according to the status of command byte. If the data frame received is the inquiry instruction, the leakage detection data collected by the system will be sent to the upper computer. In addition, the system will automatically reload if it does not receive the operation instruction from the upper computer again during the time when the independent watchdog reloads the value.

\section{Design and dynamic simulation analysis of hydraulic propulsion system}


Due to the reasonable spatial arrangement of the propeller, the mobile drilling rig can move freely in the near seabed. No matter how the drilling rig moves, there is a corresponding thrust or torque output by the propeller, and the combined force of all thrusters is greater than the resistance of its navigation in the sea.

3.1 Working principle of the propulsion system

In order to realize the independent movement with three degrees of freedom, 6 thrusters are selected to be distributed on the mobile drilling rig, among which, two horizontal thrusters mainly control the moving direction, while and four vertical propellers mainly control the vertical lifting and horizontal movement of the mobile drill rig. According to Newton's third law, as the propeller spins, it also applies a reaction force to the mobile drilling rig, causing it to rotate in the opposite direction. In order to avoid the rotation of the rig, two adjacent propellers rotate in opposite directions, as shown in Figure 5.According to the actual process, the mechanical model of the system is presented, as shown in Figure 6. When the rotation speed of No. 1 and No. 2 propellers is reduced or the rotation speed of No. 3 and No. 4 propellers $s$ increased, the drilling rig will generate forward force to make itself move forward; on the contrary, when the rotation speed of No. 1 and No. 2 propellers is increased or the rotation speed of No. 3 and No. 4 propellers is reduced, the drilling rig will generate backward, causing itself to move backward. In addition, the drilling rig can dive or rise when four vertical propellers rotate at the same speed.

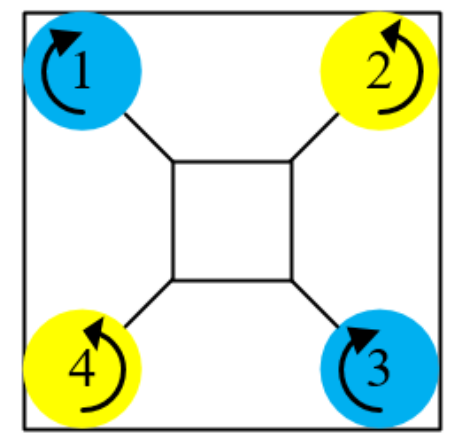

Figure 5. The rotating direction of propellers

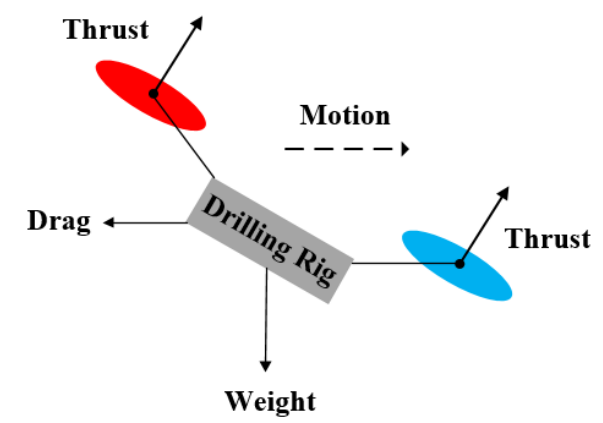

Figure 6. The mechanical model of the system

\subsection{Design of the hydraulic propulsion system}

Common hydraulic drive system usually includes pump-controlled hydraulic system and valvecontrolled hydraulic system. The pump-controlled hydraulic system can operate the actions of actuators by increasing or decreasing the flow rate of the hydraulic pump. Although it has high efficiency, its control performance is poor and cannot satisfy the control requirements well. The valve-controlled hydraulic system is generally used in open system, which can control the actions of actuators by flow of proportional valve or servo valve. It has some advantages, including the energy saving, low heat 
generation, and precise control. The disadvantage, however, is that this method would make the hydraulic system become complex, thereby increasing costs [11-13].

Since the pressure and flow of hydraulic propulsion system vary greatly, the hydraulic propulsion system in this paper adopts the mixed control hydraulic system of pump and valve, combining the advantages of the two method, which can ensure that the hydraulic propulsion system can have a good dynamic response performance. Furthermore, the flow adaptive hydraulic pump is used to make the output flow of system always match the flow required by the hydraulic components, so as to reduce the excess flow and the overflow loss of the hydraulic system, thereby improving the system effectiveness [14].

Constant pressure variable pump is applied to hydraulic system, which can continuously provide hydraulic oil with constant pressure for hydraulic propulsion system, and adjust the output flow of the system according to the flow required by the workload. Since the mobile drilling rig transmits instructions and data through the cable and the console in both directions, electro-hydraulic proportional technology is adopted in the hydraulic propulsion system, in order to accurately control the speed of propellers. The electro-hydraulic proportional pressure reducing valve is used to limit the hydraulic pressure of propeller, while the electro-hydraulic proportional flowrate regulating valve is applied for adjusting oil flow of the branch to satisfy the requirements of the propeller [15-17]. According to the actual working process, the hydraulic schematic of a single propeller is presented, as shown in Figure 7. In order to enable propeller output accurate speed, the real-time speed measured by the speed sensor is uploaded to the console through the cable and compared with the target speed, and then the deviation processed by the control system is fed back to proportional valve for real-time adjustment.

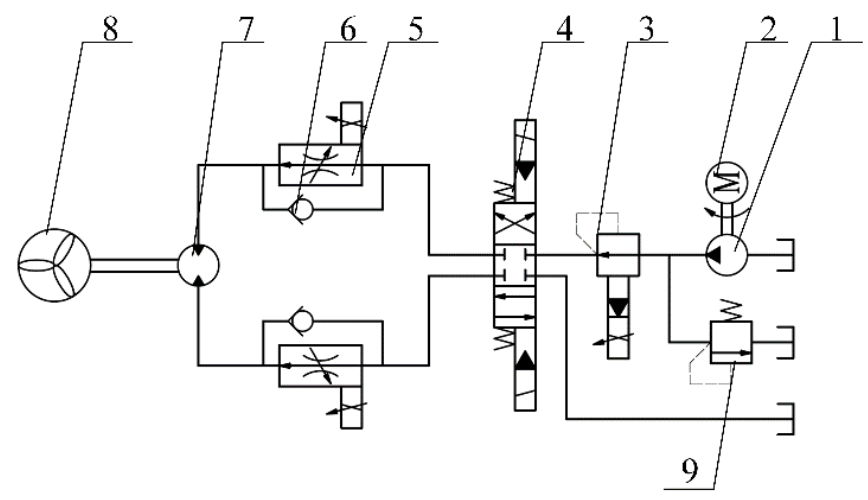

Figure 7. The hydraulic schematic of single propeller

1-hydraulic pump, 2-underwater motor, 3-electro-hydraulic proportional pressure reducing valve, 4electromagnetic directional valve, 5-electro-hydraulic proportional flowrate regulating valve, 6-check valve, 7-hydraulic motor, 8-propeller, 9-relief valve

\subsection{Dynamic simulation analysis of the hydraulic propulsion system based on AMESim}

(1) Modeling and analysis of hydraulic unit

It can be seen from the Figure 7 that the hydraulic propulsion system of the mobile drilling rig is mainly composed of hydraulic station, electro-hydraulic proportional flowrate regulating valve, electrohydraulic proportional pressure reducing valve, propeller and other related hydraulic accessories. Since there is no standard component model of proportional flowrate regulating valve, proportional pressure reducing valve as well as the standard element model of propeller in the AMESim hydraulic library, it is necessary to build the required hydraulic unit by the library of hydraulic component according to physical structure and working principle. Next, it is verified by simulation to observe whether the performance of the built component model is consistent with the performance of the real object. 
According to the actual working principle [18], the simulation model of electro-hydraulic proportional pressure valve is presented, as shown in Figure 8. This proportional pressure valve is the three-position four-way directional control valve, and its specific parameters are presented as follows. The diameter of this proportional valve 1 is $10 \mathrm{~mm}$, the maximum working hydraulic pressure of the oil inlet $(\mathrm{P})$ is $315 \mathrm{bar}$, the maximum allowable flow rate of the oil circuit is $120 \mathrm{~L} / \mathrm{min}$, and the power voltage is $24 \mathrm{~V}$. The parameters of model component are set with reference to the actual structure of proportional pressure valve. Based on the data analysis through AMESim software, the relationships between output pressure and input voltage are obtained during working process, as shown Fig 9. The simulation analysis results show that the output pressure increases with the increase of the input voltage.

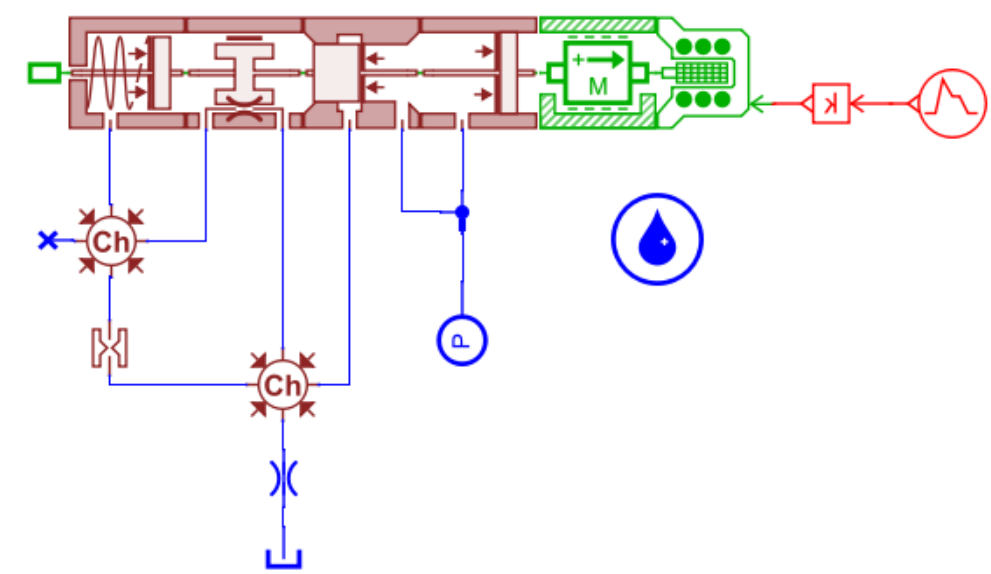

Figure 8. Simulation model of electro-hydraulic proportional pressure valve

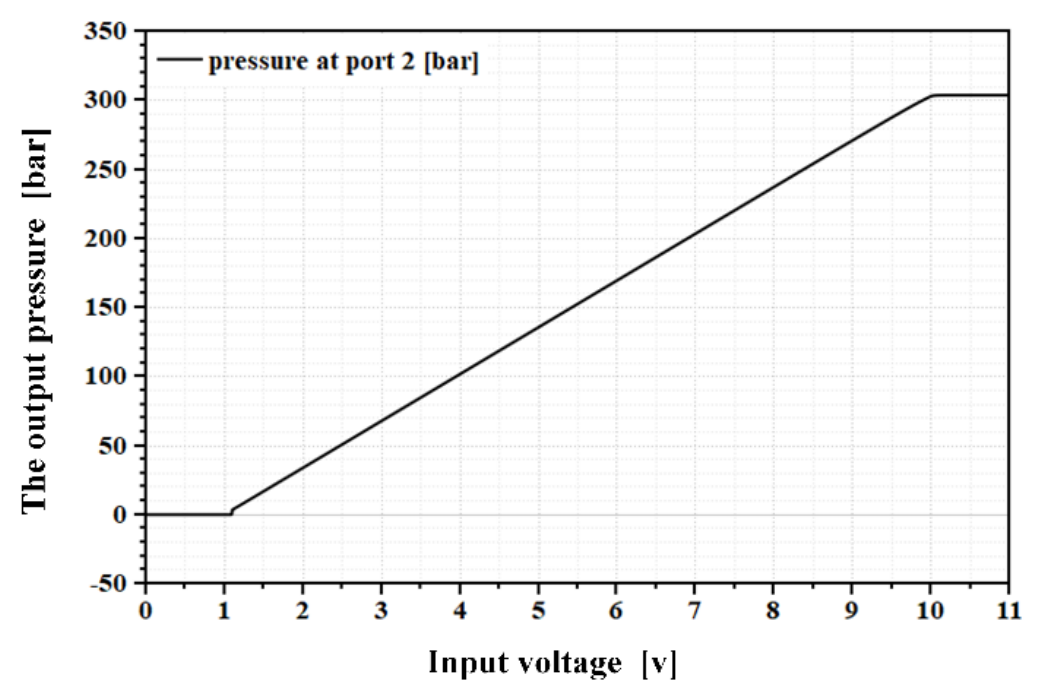

Figure 9. Relationship curve of output pressure and input voltage

The proportional flowrate regulating valve a combination of proportional throttle valve and differential pressure reducing valve through series connection, which can change the area of the orifice to control the flow rate through the electrical signal [19-20]. Since the flow rate of the throttle is related to the pressure difference between the inlet and outlet of the throttle valve, it will inevitably lead to change in pressure and eventually lead to change in flow rate when the load changes. As a result, the regulation of the oil flow rate by the proportional throttle valve is not very precise. In order to compensate for this flow deviation, a differential pressure reducing valve is used to keep the pressure difference between the inlet and outlet of the throttle valve unchanged, thus achieving precise control of the flow rate by electrical signal. According to the actual working principle, the simulation model of electro-hydraulic 
proportional flowrate regulating valve is presented, as shown in Figure 10. Its specific parameters are presented as follows. The diameter of this proportional valve 1 is $10 \mathrm{~mm}$, the maximum allowable flow rate of the oil circuit is $45 \mathrm{~L} / \mathrm{min}$. Based on the data analysis through AMESim software, the relationship between output flow rate and input voltage is obtained during working process, as shown Fig 11. The simulation analysis results show that the output pressure increases with the increase of the input voltage. The flow rate is $0 \mathrm{~L} / \mathrm{min}$ when the voltage is less than $3 \mathrm{v}$, and the maximum output flow rate is $45 \mathrm{~L} / \mathrm{min}$ when the voltage is $10 \mathrm{v}$, which is basically consistent with the steady-state flow rate curve.

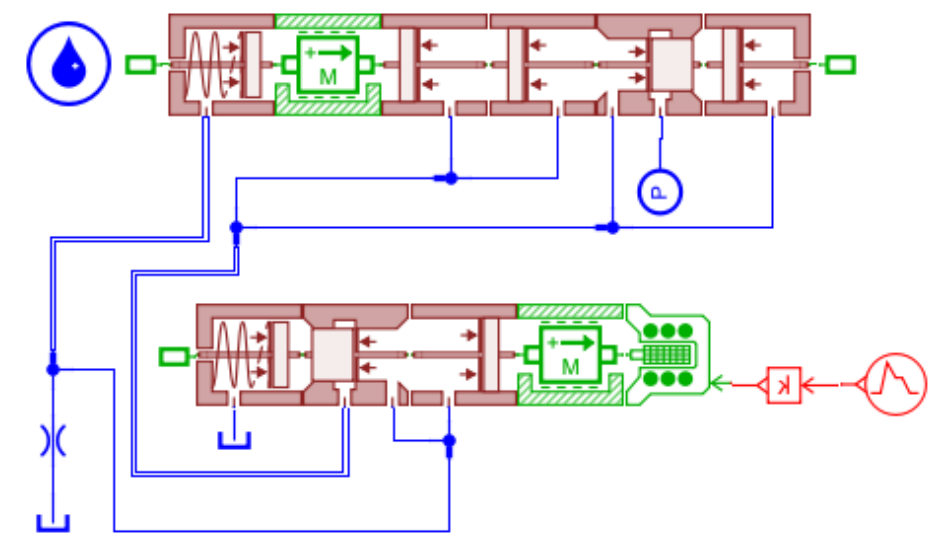

Figure 10. Simulation model of electro-hydraulic proportional flowrate regulating valve

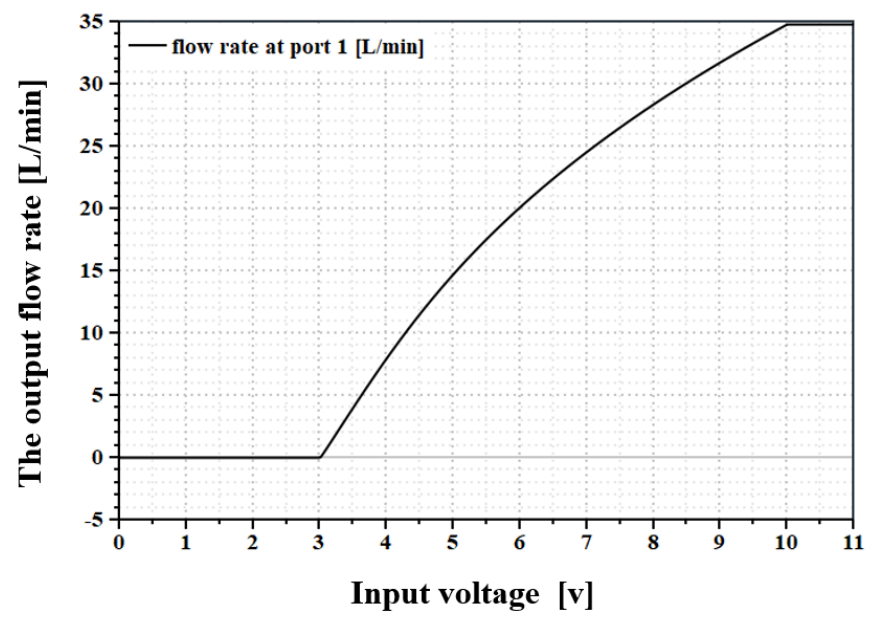

Figure 11. Relationship curve of output flow rate and input voltage

(2) Dynamic simulation of hydraulic system

The simulating systems are modeled without regard to the hydraulic components of the propulsion system, such as pressure gauge, filter, and relief valve for overload protection, which have little influence on the simulation results. At the same time, the model components of the system hydraulic station can be replaced by hydraulic components with the same functionality from the hydraulic library. Since the hydraulic control circuit and control method are the same for each propeller, the entire hydraulic propulsion system can be analyzed by the simulation analysis of a single propeller. The simulations of hydraulic propulsion system are respectively presented on the basis of theoretical model, both closedloop control and PID control.

Firstly, the hydraulic propulsion system of a single propeller is numerically simulated with the method of closed-loop control. The working principle of closed-loop is shown in Figure 12. When the proportional pressure valve and flowrate regulating valve receive the control command number, the 
pressure and flow rate of the oil flowing into the propeller is regulated to reach the target speed of rotation. During the regulating process, the real-time rotational speed detected by the rotary speed sensor is compared with the target rotational speed, and the deviation is then applied to the proportional pressure valve and flowrate regulating valve, so as to adjust the oil pressure and flow rate again. The cycle process is infinite, and finally the rotational speed is infinitely close to the target rotational speed. Based on the above working principle of hydraulic propulsion system, the simulation model is established with the method of closed-loop control, as shown in Figure 13.

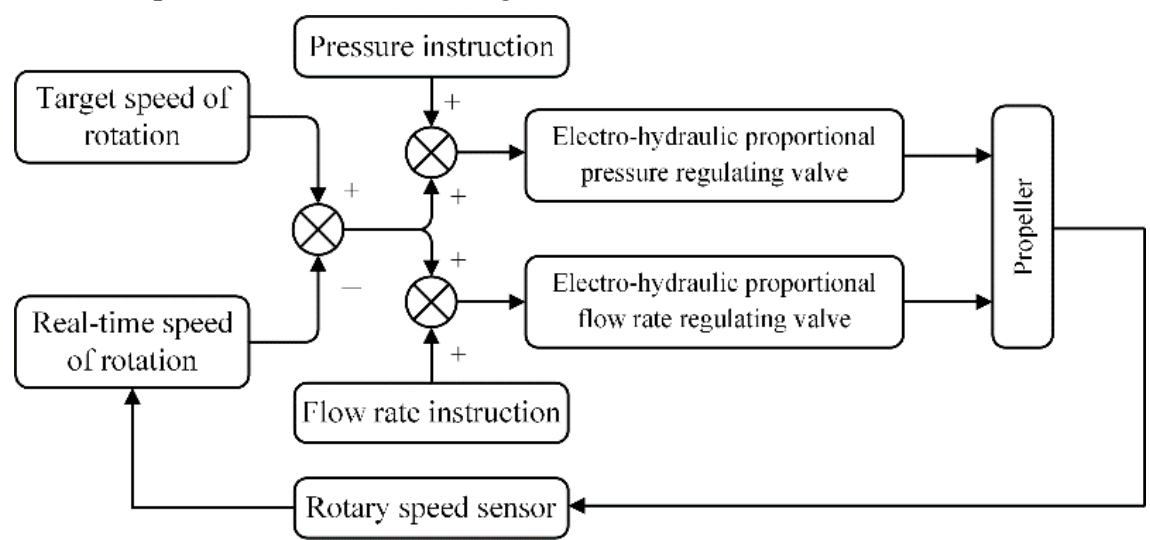

Figure 12. The working principle of closed-loop

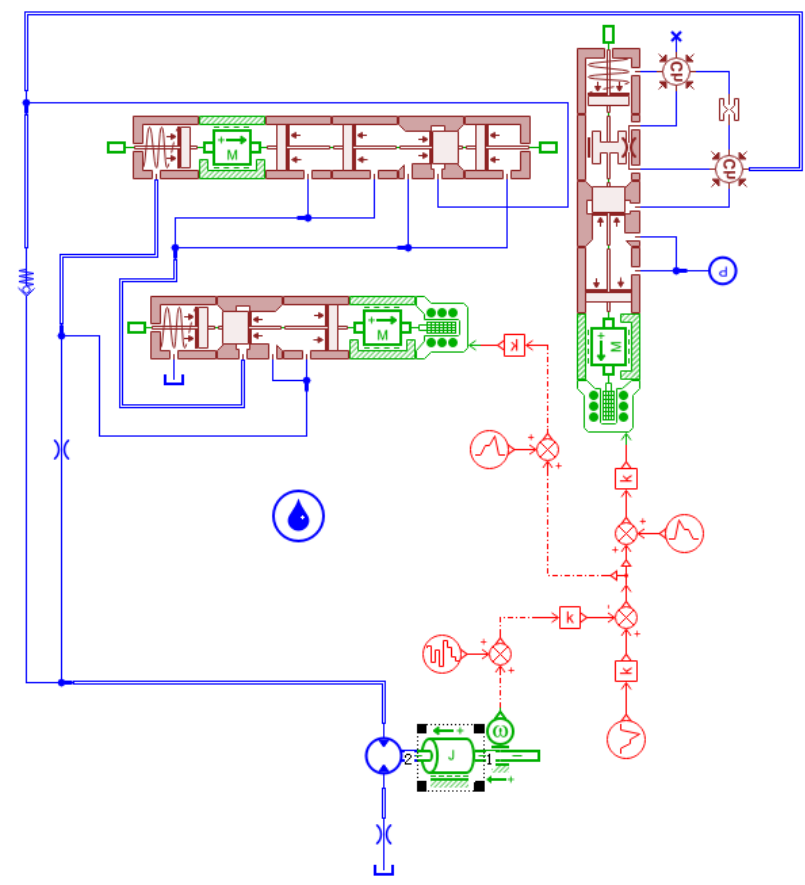

Figure 13. Simulation model of with the method of closed-loop

Since the output rotational speed of the propeller is simulated when the mobile drilling rig is moving, the target rotational speed is set at $1000 \mathrm{r} / \mathrm{min}$. Taking into account the impact of the marine environment on the propeller, a random interference signal is added to the signal transmission line of the speed sensor, the positive and negative amplitude of which is $10 \%$ of the target rotational speed, and the maximum and minimum values are respectively positive and negative. Other parameters remain basically unchanged. Based on the data analysis through AMESim software, the relationship between real-time rotational speed and time is obtained during working process, as shown in Fig 14. The simulation analysis result shows that output rotational speed of the propeller is basically close to the target rotational speed, but the 
rotational speed is in fluctuation from the beginning to the end of the simulation, and there is a large amount of over-adjustment. Therefore, we can know that it is difficult to justify the performance of the hydraulic propulsion system in terms of design with the method of closed-loop control.

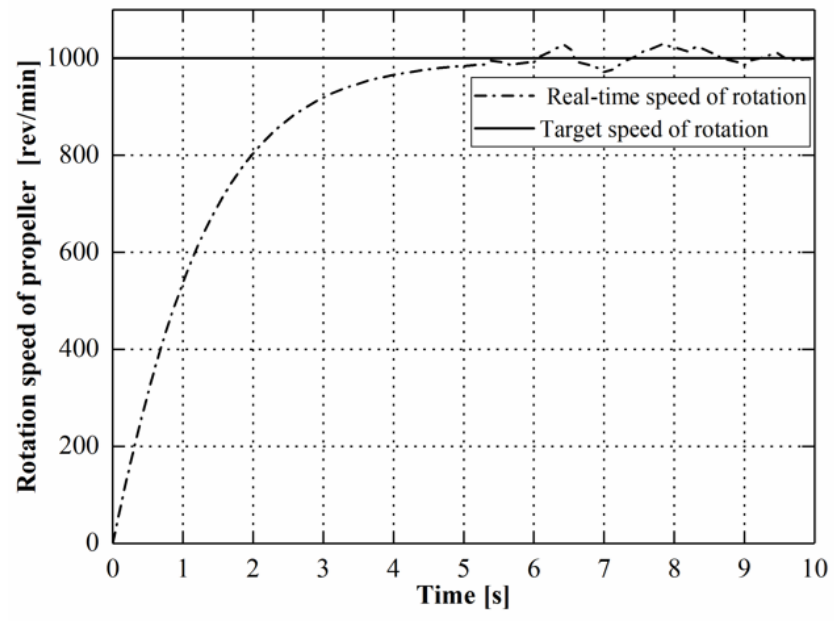

Figure 14. Relationship curve of real-time rotational speed and time with the method of closed-loop control

The method of PID control is adopted to simulate the sampling process to deal with the above problem. The AMESim software is characterized by its ability to use various model libraries in AMESim to design the required system, thus achieving the purpose of simulation [23]. Matlab $\backslash$ Simulink is widely used in many fields due to its powerful numerical processing capability [24]. With the joint simulation technology, AMESim's excellent simulation functions of fluid mechanics can not only be fully utilized, but also the powerful numerical processing function of Matlab $\backslash$ Simulink can be used to achieve the best simulation results [25-26]. The PID controller is to control the proportional (P), integral (I) and differential (D) deviation to meet the control requirements [27-28].

The PID controller is a negative feedback regulation mechanism, composed of operational amplifiers, capacitors and resistors, which is widely used in industrial control systems. As a classic traditional controller, its advantages are mainly in its simple structure, relatively strong robust control, and easy implement in actual operation. The basic theory of PID control is presented that the deviation between real-time data with the target value is transformed into proportional, integral and differential respectively, and then superimposed on an input control object to control its output, which is an infinite loop control process [29].

The mathematical equation for PID control equation can be expressed as:

$$
u(t)=K_{p}\left[e(t)+\frac{1}{T_{i}} \int_{0}^{t} e(t) d t+\frac{T_{d} d e(t)}{d t}\right]
$$

where $u(t)$ is control quantity of controlled object; $K_{p}$ is proportional factor; $T_{i}$ is integral time constant; $T_{d}$ is differential time constant; $e(t)$ is control deviation.

The deviation between the real-time rotational speed and the target rotational speed should be processed by the PID controller and then fed back to the proportional pressure valve and proportional flowrate regulating valve, so that the real-time rotational speed can be closer to the target rotational speed. According to above working principle, the simulation model is established with the method of PID control, as shown in Figure 15. And the model of control system is shown in the Figure 16. 


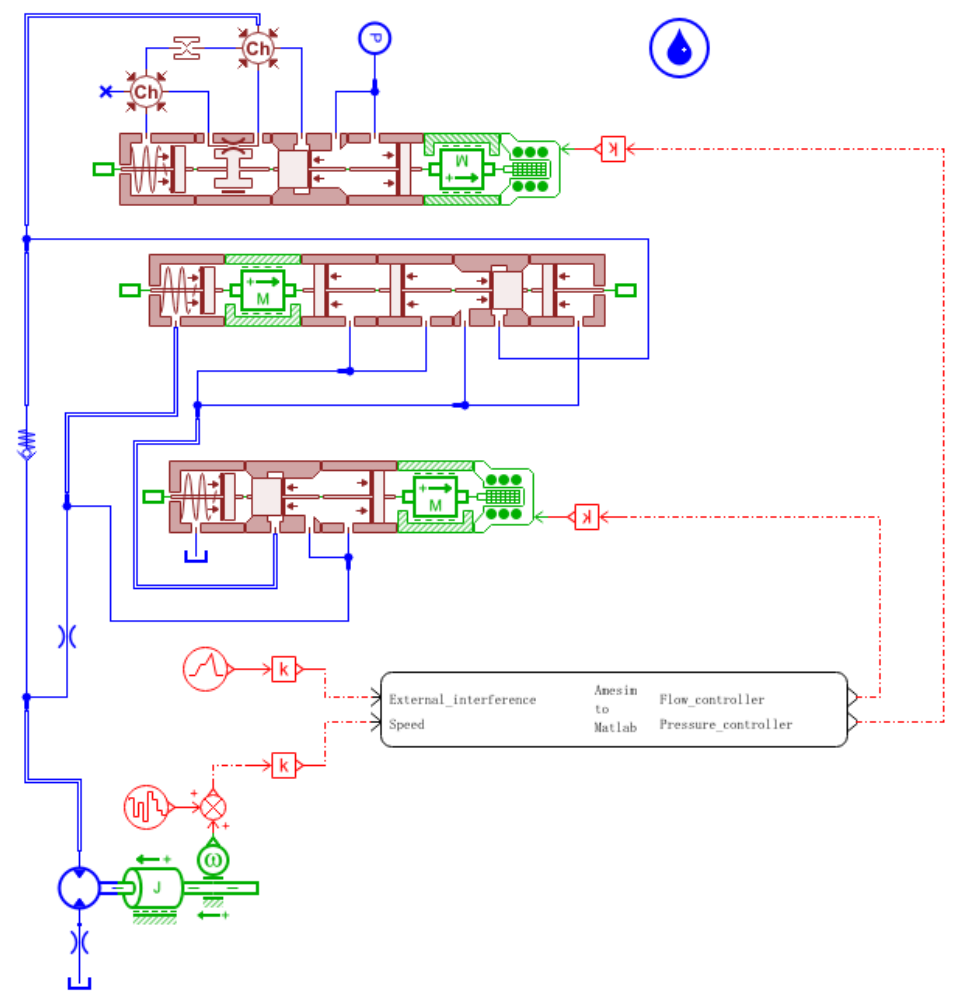

Figure 15. Simulation mode with the method of PID control

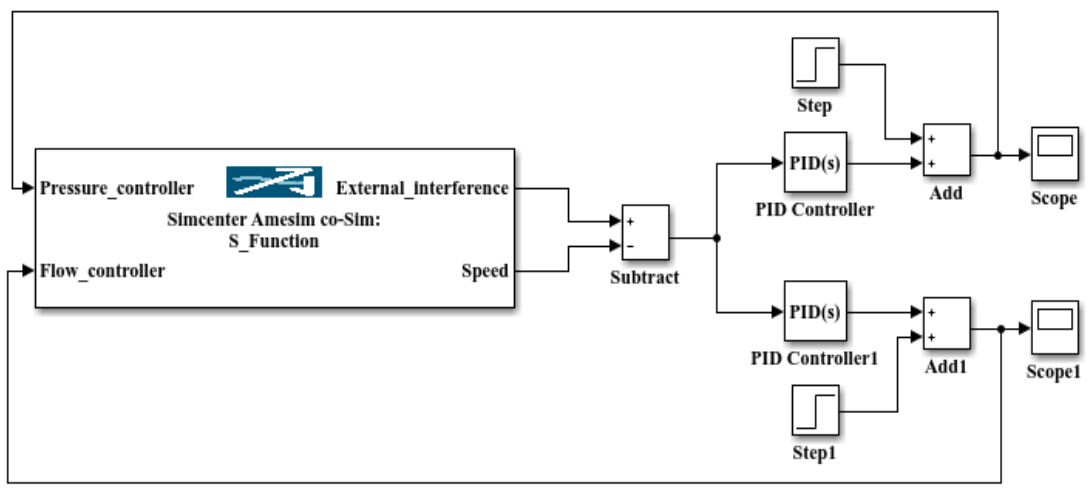

Figure 16. Model of control system

Based on the data analysis through both AMESim and Matlab $\backslash$ Simulink software, the relationship between real-time rotational speed and time is obtained during working process, as shown in Fig 17. The simulation analysis result shows that output rotational speed of the propeller is basically close to the target rotational speed. Through comparison with the method of closed-loop control, we can know that the adjustment time of rotational speed is less. In terms of accuracy, the rotational speed adjusted by the method of PID control can quickly tend to the target speed and the error is small. Based on simulation analysis results, hydraulic propulsion system controlled by PID control can meet propulsion requirements of mobile drilling rig, which provides a suitable control method for motion simulation of other freedom degrees for mobile drilling rig. 


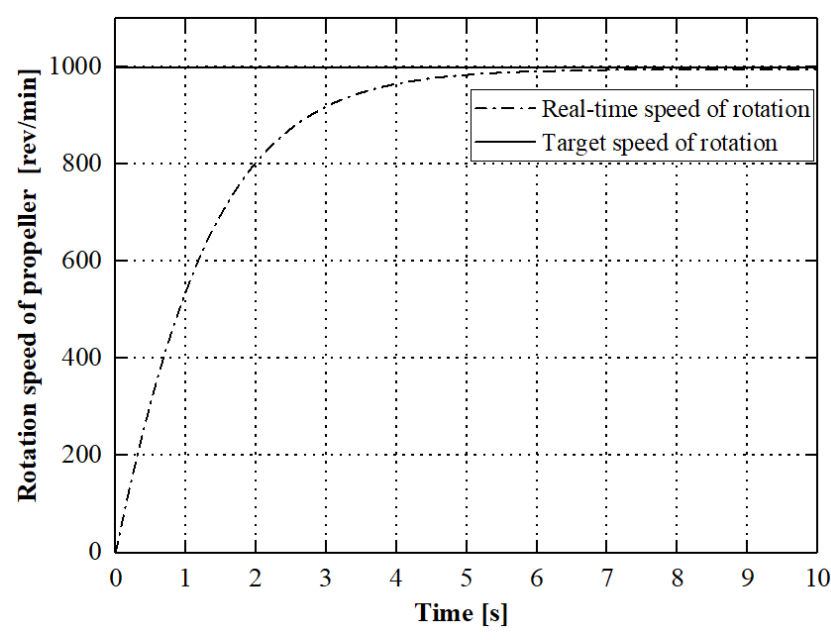

Fig 17. Relationship curve of real-time rotational speed and time with the method of PID

\section{Deep sea coring test of the mobile drilling rig}

Based on theoretical analysis and simulation analysis results, the mobile drilling rig is designed whose parameters are follows: the maximum weight is $2000 \mathrm{~kg}$ and the maximum core is $1.5 \mathrm{~m}$. In addition, it equipped with visualization system and propulsion system can move near the seabed to choose exploration sites independently. From 10 April to 9 May 2019, several experimental investigations were carried out during the deep sea exploration voyage of the R/V Haiyang 6, which was organized by Guangzhou Marine Geological Survey in China. The Figure 10 shows the drilling rig operating onboard during a sea trial. Due to the success of sea trials, the mobile drilling rig was applied during the 55th Voyage of China Oceanic Scientific Expedition supported by China Ocean Mineral Resources R\&D Association from 6 September to 23 October 2019. A large number of cobalt-rich crust cores were obtained in the area of cobalt-rich crust exploration contract between China and International Seabed Authority. A total of 76 sites were sampled within 24 days through the drilling rig and two kinds of drilling rig for seabed shallow strata, including 70 sites of $1.5 \mathrm{~m}$ depths and 6 sites of $6 \mathrm{~m}$ depths. Based on the cores of cobalt-rich crust, scientists can estimate the amount of cobalt-rich crust resources, which provides basic data for future marine geological science research and resource estimation. The Figure 19 shows underwater photograph of plate curst and cores of plate crust.

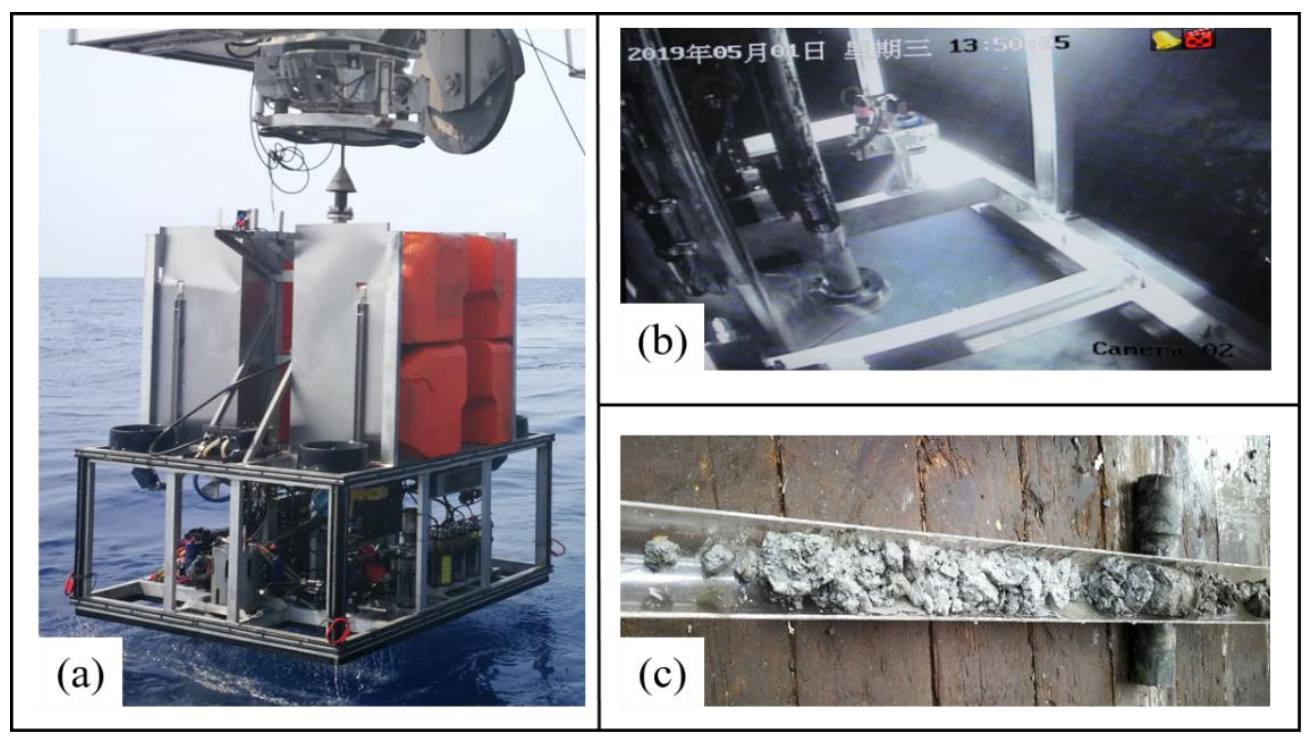

Fig 18. Photographs of sea trial in May 2019. (a) The mobile drilling rig is ready to descend into the 
ocean by lifting device; (b) The drilling rig is finding a suitable exploration site; (c) The $1.0 \mathrm{~m}$ long core of carbonate crust.

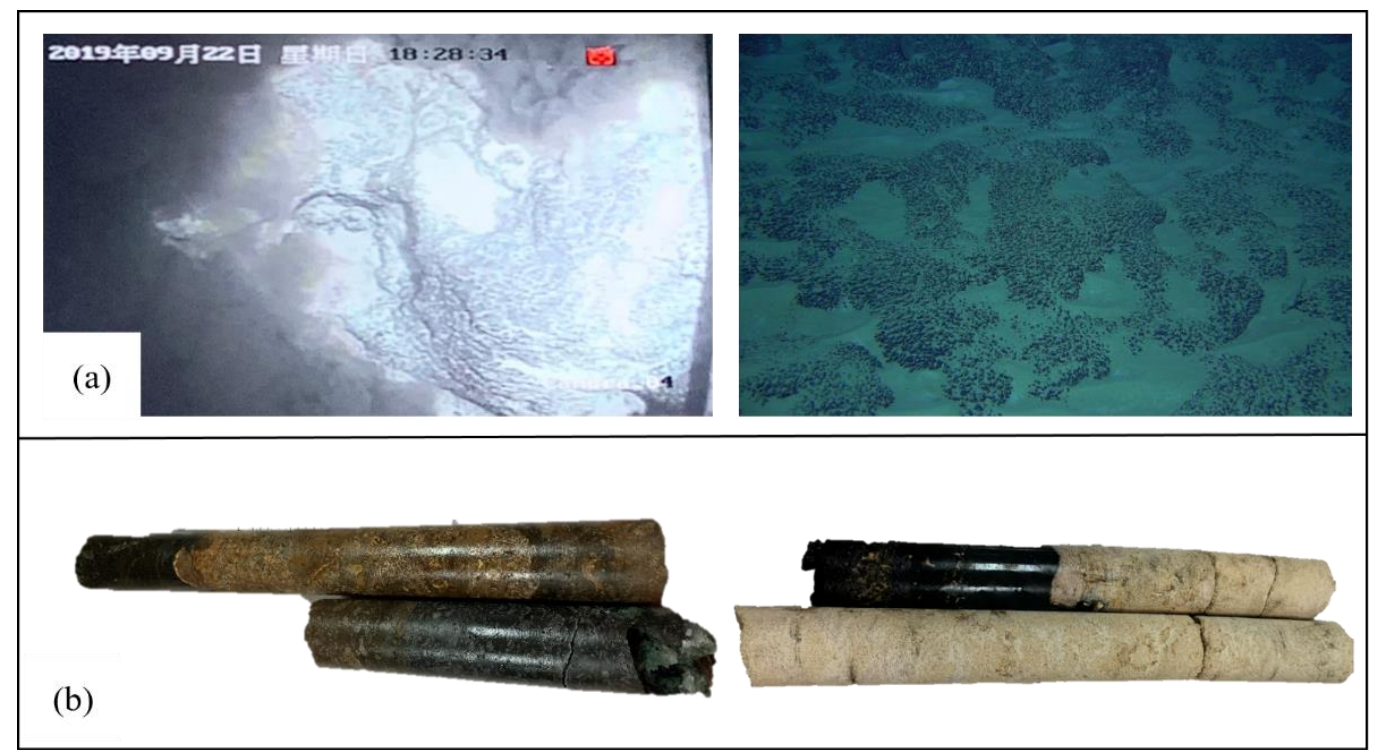

Fig 19. Photographs of sea trial in September 2019. (a) Underwater photograph of plate curst; (b) Cores of plate crust and substrate rock

\section{Conclusion}

In this paper, the mobile drilling rig is proposed to acquire the seafloor core (up to $1.5 \mathrm{~m}$ long). Based on the function of the AMESim and Matlab/Simulink software, the hydraulic propulsion system model of mobile drilling rig is established and simulated. Moreover, the control methods of closed-loop and PID are respectively used to control the hydraulic propulsion system for simulation analysis. Through the comparison of simulation results, it is found that the PID control method is more convincing in verifying the design rationality of hydraulic propulsion system, which provides a suitable control method for motion simulation of other freedom degrees for mobile drilling rig. On the basis of theoretical analysis and simulation analysis results, the mobile drilling rig was designed and tested in 2019. In its verification deployment in the South China Sea, the mobile drilling rig was operated for many times at different depths, and some cores had been successfully obtained, which verified the feasibility of this equipment. Furthermore, the mobile drilling rig was used during the 55th Voyage of China Oceanic Scientific Expedition supported by China Ocean Mineral Resources R\&D Association. Several sites were explored and a large number of cobalt-rich crust cores were obtained, which provided powerful support for the further research on survey of the abyssal resource.

Acknowledgements

We are grateful to the help of all crews of the R/V Haiyang 6, as well as excellent technical support of the Guangzhou Marine Geological Survey (GMGS) in China during the sea trial. In addition, we also thank the anonymous reviewers for their detailed and valuable comments which strengthened this manuscript. This study was supported by "the Fundamental Research Funds for the Central Universities”. 


\section{References}

[1] Hein J R, Mizell K, Koschinsky A, et al. Deep-ocean mineral deposits as a source of critical metals for high- and green-technology applications: Comparison with land-based resources[J]. Ore Geology Reviews, 2013, 51:1-14.

[2] Hein J R, Koschinsky A. 13.11-Deep-Ocean Ferromanganese Crusts and Nodules [J]. Treatise on Geochemistry (Second Edition), 2014, 13:273-291.

[3] Usui A, Someya M . Distribution and composition of marine hydrogenetic and hydrothermal manganese deposits in the northwest Pacific [J]. Geological Society London Special Publications, 1997, 119(1):177-198.

[4] Freudenthal T, Wefer G. Shallow drilling in the deep sea: The sea floor drill rig MeBo[C]// Oceans. IEEE, 2009.

[5] Tim F, Gerold W. Scientific Drilling with the Sea Floor Drill Rig MeBo [J]. Scientific Drilling, 2007(5):63-66.

[6] Report from a Workshop: Requirements for a Robotic Underwater Drills in U.S. Marine Geologic Research, 3-4 Nov 2000, Texas A\&M University.

[7] Petersen S , Herzig P M , Kuhn T, et al. Shallow Drilling of Seafloor Hydrothermal Systems Using the BGS Rockdrill: Conical Seamount (New Ireland Fore-Arc) and PACMANUS (Eastern Manus Basin), Papua New Guinea[J]. Marine Georesources \& Geotechnology, 2005, 23(3):175-193.

[8] Yugang Ren, Yanjun Liu and Zhongjun Ding. Analysis on the Development Status of Small Core Sampling Drill Based on Deep-Sea Vehicles [J]. Journal of Ocean Technology, 2019, 038(003):92-99.

[9] Wan B , Zhang G , Huang X . Research And Development of Seafloor Shallow-hole Multi-coring Drill[C]// International Society of Offshore and Polar Engineers, 2010:588.

[10] Wan B, Jin Y, Huang X . Development of 20 m Seafloor Core Sampling Drill [J].Ocean Engineering Equipment and Technology, 2015, 2 (01):1-5.

[11] Qing W , University S Y . Design of Driving System of Flameproof Hydraulic Concrete Mixer[J]. Coal Mine Machinery, 2017.

[12] Dueckinghaus H, Strieker N, Schlichting D, et al. Hydraulic system for a self-propelled harvesting machine[J]. 2010.

[13] Ferrari A, Mittica A, Spessa E . Benefits of hydraulic layout over driving system in piezo-injectors and proposal of a new-concept CR injector with an integrated Minirail[J]. Applied Energy, 2013, 103(MAR.):243-255.

[14] Ha Tham Phan, Seiya Itagaki, Yasukazu Sato. Development of Hydraulic Pump Drive System Using Switched Reluctance Motor with Servo Function. 2020, 32(5):984-993.

[15] Pang,Y. J., Yang, L. C., Li, H. W. and Cao, K., 2009. Approaches for predicting hydrodynamic characteristics of submarine objects, Journal of Harbin Engineering University, 30(8): 903 908

[16] Ridao, P., Tiano, A., El-Fakid, A., Carreras, M. and Zirilli, A. On the identification of non-linear models of unmanned underwater vehicles [J]. Control Engineering Practice, 2004.

[17] P. Sayer. Hydrodynamic loads during the deployment of ROVs. Ocean Engineering. Volume 35, Issue1, January 2008, 41 46.

[18] Maiti R, Saha R, Watton J . The static and dynamic characteristics of a pressure relief valve with a proportional solenoid-controlled pilot stage [J]. Proceedings of the Institution of Mechanical Engineers -- Part I, 2002, 216(2):143-156.

[19] R Maiti, R Saha, J Watton. The static and dynamic characteristics of a pressure relief valve with a proportional solenoid-controlled pilot stage [J]. Proceedings of the Institution of Mechanical Engineers, 
Part I: Journal of Systems and Control Engineering, 2002, 216(2):143-156.

[20]R. Amirante, A. Innone, L.A. Catalano. Boosted PWM open loop control of hydraulic proportional valves [J]. Energy Conversion and Management, 2008, 49(8):2225-2236.

[21] Franklin G, Davidpowell J , AbbasEmami-Naeini, et al. Feedback control of dynamic systems[M]. Addison-Wesley, 2003.

[22] Krus P, Weddfelt K, Palmberg J O . Fast Pipeline Models for Simulation of Hydraulic Systems [J]. Journal of Dynamic Systems Measurement \& Control Trans Asme, 1994, 116(1):132.

[23] Marquis-Favre W , Bideaux E, Scavarda S . A planar mechanical library in the AMESim simulation software. Part I: Formulation of dynamics equations [J]. Simulation Modelling Practice \& Theory, 2006, 14(1):25-46.

[24] Selmi T , Bouzguenda M , Gastli A, et al. MATLAB/Simulink Based Modelling of Solar Photovoltaic Cell[J]. International Journal of Renewable Energy Research, 2012, 2(2):213-218.

[25] Zhao R Y , Wang X . Research on Power Adaptive Control Method for Hydraulic Motor Grader Based on Simulink/AMESim [J]. Applied Mechanics and Materials, 2012, 135-136.

[26] Zhifu W , Jun F , Zhijian S, et al. Study on Speed Sensor-less Vector Control of Induction Motors Based on AMEsim-Matlab/Simulink Simulation[J]. Energy Procedia, 2017, 105:2378-2383.

[27] Huayong Y, Hu S , Guofang G, et al. Electro-hydraulic proportional control of thrust system for shield tunneling machine[J]. Automation in Construction, 2009, 18(7):950-956.

[28] Ang K H , Chong G , Li Y . PID Control System Analysis, Design, and Technology [J]. IEEE Transactions on Control Systems Technology, 2005, 13(4):p.559-576.

[29] Salvador Alcántara Cano, Ramon Vilanova Arbós, Carles Pedret i Ferré. PID Tuning:A Modern Approach via the Weighted Sensitivity Problem. 2020. 